\title{
The Research on Design and Application of Blended Learning Mode Based on Smart Vocational Education Cloud Platform
}

\author{
Xue-Feng ZHAO ${ }^{a}$, Dong-Tao SUN ${ }^{b}$ \\ ${ }^{1}$ Binzhou Polytechnic, Shandong University, P.R. China \\ a780583544@qq.com, b1354646339@qq.com
}

\begin{abstract}
Keywords: blending learning, learning mode, Intelligent Cloud of Vocational Education Cloud Platform

Abstract. Blending learning organically combines traditional teaching with online learning, which has the great significance to improve learners' initiative and innovation in learning. There are, however, still some problems in the practical application of blending learning in colleges and universities in our country, such as the insufficient utilization of new media technology and the unobvious dominant position of students. In this study, in order to solve the problem, the ICVE(Intelligent Cloud of Vocational Education) Cloud Platform is used as a tool of blending learning, and a mode of blending learning based on the ICVE Cloud Platform is designed to actively explore and solve the fusion problem between online learning and classroom learning, so as to promote the theoretical and practical research of blending learning.
\end{abstract}

\section{Introduction}

Blending learning combines traditional teaching with online learning in order to form a model of blending learning with students as the main body, teachers as supervision, guidance and organization, so as to realize the complementary advantages between the two. It not only preserves the advantages of traditional teaching, such as dominance and systematicness, but also makes full use of the resource advantages of online learning to cultivate the autonomous learning ability of students, which provides a new mode for teaching reform and has been widely concerned and applied by people. The ICVE Cloud Platform is a new type of interactive platform for education developed by higher education press, which integrates information technology into the teaching process by using convenient and fast tools and methods, as well as provides intelligent and databased supports and services for the teaching process. Moreover, it has solved the problems of low participation in the class, non-smooth interaction between teachers and students, incomplete data collection and non-implementation of online education in the process of teaching in colleges and universities.

This paper will discuss the blending learning by using the ICVE Cloud Platform, and construct a mode of blending learning based on the ICVE Cloud Platform, which makes full use of the application of information technology to run a variety of interactive forms through every link of the teaching process, so as to improve the self-learning ability of students and provide a learning platform for the personalized learning of them.

\section{Introduction to the Mode of Blending Learning and the ICVE Cloud Platform}

\subsection{The mode of blending learning}

Blending learning promotes the existing conceptions on learning, which changes the cognitive style of students as well as the teaching mode, teaching strategies of teachers and the role played by them. According to the research of scholars at home and abroad, the blending learning can be defined as a teaching mode which combines traditional classroom teaching and extracurricular online learning, as well as fuses learning theory, learning resources, learning methods and other elements under the guidance of the concept of "teacher-led, student-oriented", in order to achieve the best learning effect for students. The blending learning mode can be divided into three stages: front-end analysis as well as the design of activity resource and teaching evaluation. The front-end analysis fully understands the learning style, learning preference and other 
related learning characteristics of learners through the analysis of their characteristics, learning objectives and environment, sets specific and reasonable teaching objectives by combining with the teaching content, and at the same time, it fully considers the implementation environment of blending learning, so as to provide the basis for the subsequent teaching activities and resource design. The design of activity and resource is composed of three links: the overall design of blending learning, the design of unit activity as well as the design and development of resource. The design of teaching evaluation mainly evaluates the teaching effect by the evaluation of learning process, the examination of curriculum knowledge and the organization assessment of learning activities.

\subsection{Introduction to the ICVE Cloud Platform}

The ICVE Cloud Platform is an innovative classroom based on Internet, cloud computing technology and information teaching means, which is also a mobile teaching classroom based on mobile interconnection environment to meet the needs of classroom teaching interaction between teachers and students and immediate feedback. In addition to this, the ICVE Cloud Platform provides personalized, intelligent and data-based platform supports for teaching process, as well as the digital resources and online application services with high quality for teachers, students, enterprise employees and social learners of vocational education on the base of the sharing platform of digital teaching resource and service platform of online teaching for vocational education constructed and operated by the high education press. Meanwhile, the ICVECloud Platform can design teaching activities from three links - before class, in class and after class, and connect these three links organically, which gives a new interactive experience for the whole teaching process.

Teachers can send the learning content to the students' mobile phones through the ICVE Cloud Platform. This kind of courseware can include graphic text, video and voice explanation, and carry out various forms of teaching interaction in the classroom, while students can answer questions or feedback with mobile phone, which has greatly reduced the learning cost of teachers, and its convenience and ease of teaching provides favorable premise for the implementation of the ICVE Cloud Platform.

The ICVE Cloud Platform pays attention to providing the supports on information and technology of the teaching activities in class, actively uses the means of information push to interact face to face with students in real time, as well as carries on the tracking monitoring and the real-time evaluation to the complete teaching process through this convenient, accurate and effective interaction way. The enrich interactive function of the ICVECloud Platform provides teachers with a more open platform for the implementation of teaching, so that the teaching design can be integrated into more personalized teaching activities, which has greatly improved the interaction effect of teachers and students in teaching, and solved the practical problems such as the single interaction mode and low participation rate of students.

The ICVE Cloud Platform can record the whole teaching process in the aspect of data recording, and sets up data collection points for each link - before class, in class and after class, whose main purpose is to restore the real learning behavior of students so as to reproduce the whole teaching process. Based on the data, it evaluates the teaching situation with objective attitude and adjusts the teaching strategy with effective method.

Through creating online virtual classroom, the ICVE Cloud Platform can create an interactive and high-efficiency learning environment, which can not only realize the synchronous thinking and the real-time discussion through the interaction in the class, but also provide the students with the asynchronous learning channel that is suitable for different levels of the students, so as to realize the personalized teaching. 


\section{The Design on Mode of Blending Learning Based on the ICVE Cloud Platform}

\subsection{Principles of design}

The smooth development and implementation of the curriculum is closely related to a good and reasonable teaching design, so the construction of the blending learning mode based on the ICVE Cloud Platform needs to follow the following design principles:

\subsubsection{Take students as the main body}

We should take the development of students as the fundamental purpose of education, pay attention to every student in the class, teach students according to their aptitude and attach great importance to personality. In class, teachers organize students to carry out various, comprehensive and effective learning activities, so that students can learn fromeach other so as to promote together and make a mutualdevelopment. After class, teachers can push some online learning materials related to the course, while students can preview or consolidate professional knowledge anytime and anywhere, which can greatly improve the learning effect of students, and cultivate the autonomous learning ability of student at the same time.

\subsubsection{Integ rate various resources}

In the design of teaching mode of the ICVE Cloud Platform, we should make full use of the function of the ICVECloud Platform as the carrier of resources, pay attention to the integration of teaching resources which includes graphic and text information, video, audio, micro-class and other forms. In addition to explaining the content of knowledge points, we also need to provide students with systematic, complete and efficient learning resources, and effectively carry out autonomous learning.

\subsubsection{Focus on cooperation}

The mode of blending learning based on the ICVE Cloud Platform needs to pay more attention to the cultivation of the autonomous learning ability of students and the ability of cooperative learning among groups, while teachers act as the organizers and leaders of the study, who carry on the individualized guidance and the answering service for difficult questions to the students in every link, such as pre-class preview, teaching in class, review and consolidation after class and so on.

\subsubsection{Combination of real-time interaction and immediate evaluation}

During the course of the blending learning, we should pay attention to the learning state of students, carry on the real-time tracking and the immediate evaluation, moreover, we should fully organize topic discussion, arouse class atmosphere, carry out knowledge testing in the class, and make statistics on the test result in real time, which can not only lighten the learning burden of students, but also promote their learning concentration. At the same time, we should adhere to the principle of evaluation in real time, design specific evaluation strategy, make full use of scientific evaluation tools and methods, so as to fully integrate the evaluation from teachers and the self-evaluation of the students. It is necessary to evaluate the learning results of all students, and feedback the evaluation results in time, so as to give full play to the diagnosis, incentive and adjustment of evaluation.

\subsection{Mode Fonstruction}

According to the above design principles, it forms a mode of blending learning based on the ICVE Cloud Platform by considering the influencing factors of the online learning, learning preferences and needs, as well as learning attitude and evaluation of students, which includes three stages: front-end analysis, the design of teaching activity and learning evaluation. 


\subsubsection{Front-end Dalys is}

Front-end analysis can fully understand the relevant information of learning through the analysis on learner, learning environment, learning goal and learning content, so as to provide the basis for the follow-up teaching design.

The analysis on learner: it includes the analysis on the fundamental situation of learner, the understanding on the related knowledge of learning content, as well as the learning ability, intention and habit of learner and so on. The learning intention determines whether the learner can take the initiative to learn knowledge or not, which is the basic condition of online learning. The learning ability determines whether learners can successfully complete online learning or not. While the learning habit is the guarantee of learners' learning efficiency.

The analysis on learning content: it is the premise of teaching design, and analyzes the relationship and internal connection of learning knowledge points to get the level and structure of content. The analysis on learning content should pay attention to the relationship between the levels and structures of knowledge, which includes: the determination of content knowledge point and the learning content category, the analysis of the knowledge point structure, content evaluation, the determination of the task and so on.

\subsubsection{The Design of Waching Detivity}

The design of teaching activities is carried out from three aspects: before class, during class and after class, which combines with the resources and characteristics of online learning, gives full play to the advantages of online learning, complements with traditional teaching, and runs online learning through the whole learning process.

The design of teaching activity before class: in this stage, learner can study independently, master basic knowledge and find problems by using the ICVE Cloud Platform. Teachers collate the basic information of learning from the results of front-end analysis, including learning objectives, learning content and so on, and make a reasonable choice of learning resources, and then push the designed learning resources to students in real time through the ICVECloud Platform, so that the learner can study the basic knowledge by using the rich learning resource. According to the learning situation and students' feedback, teachers summarize the contents and understand the existing problems and learning needs of students. Learning in this way gives full play to the leading role of teachers and the main role of students. Under the guidance of teachers, learners can explore independently, solve the problems encountered in learning and complete the task so as to realize the meaning construction of knowledge.

The design of teaching activity in class: it is an important part of the whole blending learning mode to carry on the design of teaching activity based on the ICVE Cloud Platform. The activities of mobile blending learning mainly include classroom teaching, online learning, discussion interaction and so on, but these three forms of activities are not carried out alone in the actual teaching process, which should be integrated according to the learning needs of students and the teaching needs of teachers in time.

Classroom teaching is mainly completed in the middle of the class. Teachers systematically explain new knowledge in the classroom in the form of face-to-face language expression, which mainly involves learning display, situation creation, knowledge teaching, organization activities, teaching summary and so on before class; online learning is mainly carried out before and during the class, and with the support of the ICVE Cloud Platform, teachers can send students the relevant curriculum resources, learning goals, learning difficulties, pre-class knowledge test questions and so on, meanwhile, learners can carry out autonomous learning, cooperative learning, informal learning and other activities according to their own learning needs; while discussion interaction runs through the whole teaching process, which includes both offline discussions as well as the online discussions among students and between teachers and students, in which teachers mainly carry out the face-to-face activities in time according to teaching needs, or carry out various online learning activities in time with the support of ICVE Cloud Platform, such as multimedia teaching, problem feedback, real-time discussion, time-limited testing and so on. 
The design of teaching activity after class: the review after class not only needs ample learning resources, but also needs scientific teaching design, reasonable arrangement of learning tasks and learning forms. According to the needs of after-class review, this mode designs some teaching activities, such as homework push after class, feedback of difficult points, after-class test, teaching resource sharing and so on.

\subsection{Evaluation of learning}

Learning evaluation needs to reflect the learning effect and learning status of students from many aspects. From the perspective of online learning and face-to-face learning, its process runs through the whole learning process, and achieves diversified evaluation in the end. Online learning records and evaluates the situation of participation, test results, homework completion, preview and review of students. While the evaluation of face-to-face learning records and statistics from the aspects of participation, interactive results, collaborative learning, work presentation, stage test and so on. All data collection runs through the whole learning process, and each learning activity has detailed data records and generates personalized data reports, which can be used as a reference for diversified evaluation.

\section{The Analysis on Application Effect}

In order to explore the feasibility and learning effect of the blending learning mode based on the ICVE Cloud Platform in practical teaching, the author takes the course of Planning on Mobile Products and Project Management as an example to study the learning mode in practice. At the end of the course, the author investigates the learners through the form of questionnaire and interview of the ICVE Cloud Platform, which covers the attitude towards the use of the ICVE Cloud Platform teaching and the attitude towards blending learning style. This paper demonstrates the feasibility and practicability of the blending learning mode based on the ICVE Cloud Platform, and draws the research conclusion. In the aspect of the utilization of modern information technology, the ICVE Cloud Platform runs through every teaching link before class, in class and after class, supports the blending learning environment which provides resources, interactive application, monitoring and management, as well as makes full use of interactive technology and new media resources which has provided a new supporting platform for teaching. Under this mode, it is emphasized that "learning" of students as the main body, and all teaching activities are designed around students, especially in the part of classroom teaching. Each student can participate in the interaction through the interaction of ICVE Cloud Platform, which greatly arouses the learning interests and efficiency of students. The ICVE Cloud Platform can evaluate the learning state more objectively and effectively through collecting learning data as the basis of diversified evaluation during the whole process.

However, in the process of teaching practice, there are still some problems in this learning mode from the point of view of practical effect and the feedback of students, which is mainly shown in the basic functions and the design of teaching activity of the ICVE Cloud Platform. It is the focus of the design of teaching activity that how to design teaching activities for the blending learning mode based on the ICVE Cloud Platform, how to maintain the learning enthusiasm of students and arouse their learning interests in the classroom. In addition, more efforts need to be made to promote the learning autonomy and innovation of students.

\section{Conclusion}

On the basis of the blending learning theory and combined with the ICVE Cloud Platform which is convenient, easy to use, data-driven, personalized with the real-time interaction, this paper constructs a mode of blending learning based on the ICVE Cloud Platform, and carries on the application practice in the course of Planning on Mobile Product and Project Management. We find that the mode of blending learning based on Rain Classroom can take students as the center, give full play to the advantages of modern information technology, integrate classroom learning and online learning organically, as well as provide a new way to improve the learning quality and promote the teaching reform. 


\section{References}

[1]Qiliang Zhang, Ai chuan Wang. Research on a New Mixed Teaching Model Based on "Flipping Classroom", Modern educational technology. 4(2014)27-32.

[2]Guohua Wang. Analysis of the status quo of domestic mixed learning research, Distance Education in China.2(2015)25-31.

[3]Ran Chen, ChengYang. Research on SPOC Hybrid Learning Mode Design, Distance Education in China.5(2015)42-47.

[4]Wen LI. Research on the Implementation Strategy of College Mixed Learning from the Perspective of Destructive Innovation, China Educational Technology.7(2013)103-106.

[5]Ahmad AI-Huneidi, Jeanne Schreurs. Constructivism Based Blended Learning in Higher Education, Springer Berlin Heidelberg. 278(2013)581-591.

[6]Hongchun Zhou. Exploration and Practice of Hybrid Learning Mode Based on Blackboard Learning Platform, E-education Research. 2(2011) 87-98.

[7]Huanhuan Tan, Yong Zhang. Theoretical system and technical basic research of hybrid learning, Software Guide. 4(2011) 3-5.

[8]Craig Barnum, William Paarmann. Bringing Induction to the Teacher: A Blended Learning Model, T.H.E Journal. 9(2002) 56-64. 